\title{
Decline in male circumcision in South Korea
}

\author{
DaiSik Kim', Sung-Ae Koo ${ }^{2}$ and Myung-Geol Pang ${ }^{3^{*}}$
}

\begin{abstract}
Background: To investigate the changing circumcision rate in South Korea in the last decade and to propose underlying causes for this change, in the context of the present fluctuating world-wide trends in circumcision.

Methods: From 2009 to 2011, 3,296 South Korean males (or their parents) aged 0-64 years were asked about their circumcision status, their age at circumcision, and their information level regarding circumcision. We employed non-probability sampling considering the sensitive questions on the study theme.

Results: Currently the age-standardized circumcision rate for South Korean males aged 14-29 is found to be 75.8\%. In an earlier study performed in 2002, the rate for the same age group was $86.3 \%$. Of particular interest, males aged 14-16 show a circumcision rate of 56.4\%, while the same age group 10 years ago displayed a much higher percentage, at $88.4 \%$. In addition, the extraordinarily high circumcision rate of $95.2 \%$ found 10 years ago for the 17-19 age group is now reduced to $74.4 \%$. Interestingly, of the circumcised males, the percentage circumcised in the last decade was only $25.2 \%$; i.e., the majority of the currently circumcised males had undergone the operation prior to 2002, indicating that the actual change in the last decade is far greater. Consistent with this conjecture, the 2002 survey showed that the majority of circumcised males (75.7\%) had undergone the operation in the decade prior to that point. Focusing on the flagship age group of 14-16, this drop suggests that, considering the population structure of Korean males, approximately one million fewer circumcision operations have been performed in the last decade relative to the case of non-decline. This decline is strongly correlated with the information available through internet, newspapers, lectures, books, and television: within the circumcised population, both the patients and their parents had less prior knowledge regarding circumcision, other than information obtained from person to person by oral communication. Within the uncircumcised population, the prior knowledge was far greater, suggesting that information discouraging circumcision played an important role.
\end{abstract}

Conclusion: South Korean male circumcision is likely to be undergoing a steep decline. The cause for this decline seems to be the increase in information available on the pros and cons of circumcision.

Keywords: Male circumcision, South Korea, Information, HIV

\section{Background}

Male circumcision is performed primarily for religious reasons, notably in Muslim and Jewish countries. Starting from the mid-1800s, circumcision began to be practiced in English-speaking countries, although the only such country where boys are routinely circumcised at present is the United States (US).

We recently reported that South Korea has a surprisingly high circumcision rate $[1,2]$, greater than $90 \%$ in some age groups. It is the only country among its geographical and cultural neighbors in which most boys are

\footnotetext{
* Correspondence: mgpang@cau.ac.kr

${ }^{3}$ Department of Animal Science and Technology, School of Bioresource and Bioscience, Chung-Ang University, Anseong, Gyeonggi-Do, South Korea Full list of author information is available at the end of the article
}

circumcised; no other countries with strong Confucian and Buddhist traditions circumcise at this rate [1]. In fact, circumcision is against Korea's long and strong tradition of preserving the body as a gift from parents. Confucius said, "We received our body, hair, and skin from our parents and dare not harm them. This is the beginning of filiality" [3]. Christianity has never been associated with circumcision throughout its 2000-year history; in fact, Saint Paul in Galatians of the New Testament explicitly says that it is unnecessary. The recent popularity of both Protestant and Catholic Christianity in South Korea therefore cannot account for the present situation. Since there are virtually no Muslim or Jewish populations living in South Korea, all circumcisions have been cited as being performed for "medical" reasons, a

\section{Biomed Central}


view strongly influenced by the US and which became prevalent in 1945, the year of Korean independence from Japanese occupation and the beginning of US military occupation of South Korea. These conclusions were drawn in a previous study [2], where it was found that virtually no circumcision was performed before the year 1945 .

In sub-Saharan Africa, mass medical circumcision has been promoted and practiced to prevent the spread of HIV: for instance, in Tanzania, tribal circumcision is being transformed into medical circumcision [4]; in Rwanda, we see the traditionally non-circumcising nation accepting mass medical circumcision [5].

In view of the diverse global attitudes regarding circumcision, the recent decline in circumcision in the US [6] and the sharp increase in medical circumcision in sub-Saharan Africa and elsewhere [4,5,7], we investigated how the circumcision rate in South Korea has changed over the last decade.

\section{Methods}

We recruited, mainly through the internet (www. pop119.com and www.aoosung.com), subjects who were directed to a questionnaire pop-up regarding the circumcision status of themselves or their sons. Electronic mails were sent to each registered person of aoosung. com to advertise the aforementioned event. We also used off-line methods of interviewing (5.4\% of the total respondents), with the authors conducting the actual interviews, as described in our previous study conducted in 2002 [2]. The individual questions were exclusively regarding circumcision, to recruit maximum responses, and because previous studies regarding Korean circumcision revealed that the circumcision status is unrelated to religious, educational, economic, or geographical backgrounds [1,2]. Questionnaires are included in an Additional file 1. The study included 3,296 males aged 0-29 years. Circumcision status of children who were less than 18 years old was provided by their parents (Table 1). The maximum age of parents in the study was 64 years. They were questioned as to whether and when they were circumcised; from this information, we obtained the present circumcision rates along with age at circumcision. For both circumcised and uncircumcised individuals and their parents, we included questions on the age at circumcision and whether they had received various types of information, voluntary or involuntary (such as both pros and cons), regarding circumcision. The majority of the participants were recruited through the internet. The response rate was $70 \%$. All participants (or their parents) were fully informed about the survey and asked to provide informed consent. Ethical approval was obtained from the Institutional Review Board, Chung-Ang University, Seoul, Korea. The data were analyzed using the Chi-square test. Statistical significance was set at $p<0.05$.

\section{Results}

Figure 1 shows the present circumcision rates in five age groups: <13; $14-16 ; 17-19 ; 20-22$; and $23-29$ years (unbroken line) with percentages of 13.1, 56.4, 74.4, 83.9, and $80.1 \%$, respectively. While relatively high, these rates are lower across the board when compared to those from our 2002 study (broken line). For comparison, the circumcision rate of 20-year-olds as a function of calendar year is plotted in Figure 2, combining data from the present study and the previous one [2]. The present rate of $75.1 \%$ is about 17.0 percentage points lower than the $92.0 \%$ value found in 2002. The steepest increase in the circumcision rate occurred between the 1980s and 2000s, and then a substantial decrease was noted in the 2010s (Figure 2). Currently, the age-standardized circumcision rate with 2000 Korean Census Population being standard population was $75.8 \%$ for South Korean males aged 14-29. As shown in Figure 3, the age standardized rate for the same age group was $86.3 \%$ in the earlier 2002 study. Among currently circumcised males, the percentage circumcised in the last decade was only $25.2 \%$. This finding strongly suggests that the majority of currently circumcised males underwent the operation prior to 2002. In other words, much of the current circumcision rate is a carry-over from the years before

Table 1 Basic characteristics of the study participants $(N=3296)$

\begin{tabular}{|c|c|c|c|c|}
\hline & \multicolumn{2}{|c|}{ Data reported by self } & \multicolumn{2}{|c|}{ Children's data provided by their parents } \\
\hline & $\begin{array}{l}\text { Uncircumcised } \\
(\mathrm{N}=211)\end{array}$ & $\begin{array}{l}\text { Circumcised } \\
(\mathrm{N}=883)\end{array}$ & $\begin{array}{l}\text { Uncircumcised sons } \\
\qquad(\mathrm{N}=1490)\end{array}$ & $\begin{array}{l}\text { Circumcised sons } \\
\quad(\mathrm{N}=712)\end{array}$ \\
\hline \multicolumn{5}{|c|}{ Age (years) } \\
\hline$<13$ & - & - & $1229(82.5 \%)$ & $185(26.0 \%)$ \\
\hline $14-16$ & - & - & $165(11.1 \%)$ & $213(29.9 \%)$ \\
\hline $17-19$ & $32(15.2 \%)$ & $91(10.3 \%)$ & $63(4.2 \%)$ & $184(25.8 \%)$ \\
\hline $20-22$ & $50(23.7 \%)$ & $282(31.9 \%)$ & $11(0.7 \%)$ & $34(4.8 \%)$ \\
\hline $23-29$ & $129(61.1 \%)$ & $510(57.8 \%)$ & $22(1.5 \%)$ & $96(13.5 \%)$ \\
\hline
\end{tabular}

The total number $\mathrm{N}=3296$ does not correspond to the actual number of different individuals who completed their responses, because some had more than one son, and the data for males over 29 years of age were not used. The number of completed responses was 3465 , out of 4922 total responses ( $70.4 \%$ response rate). 


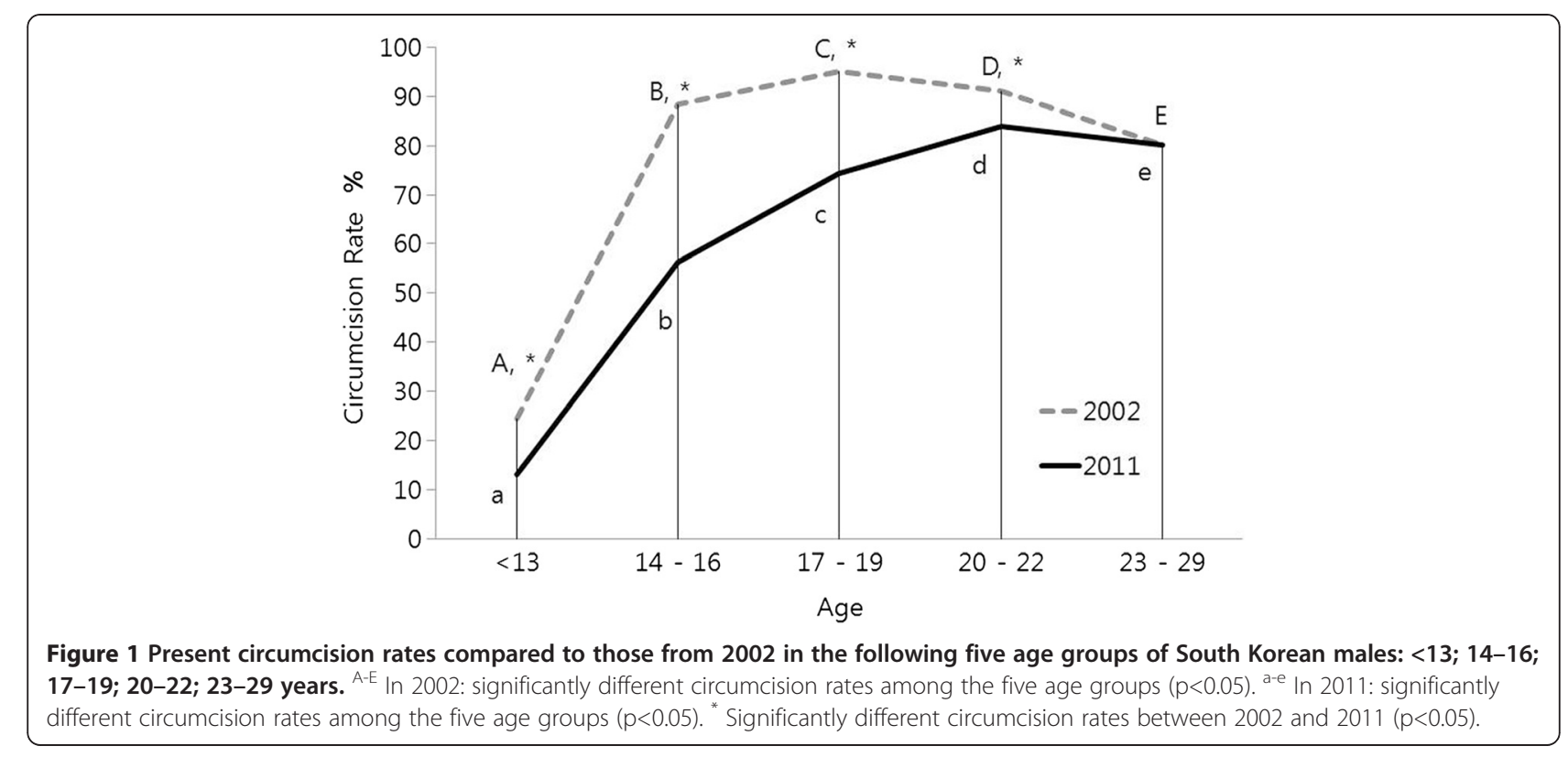

2002. In stark contrast with the present situation, the majority of circumcised males (75.7\%) in the study performed in 2002 had undergone the operation in the decade prior to that year, implying that the overall circumcision activity in South Korea was much higher than it is now.

Therefore, to identify the main cause of the decline in circumcision rate, we analyzed the correlation between circumcision status and exposure to information on circumcision. As shown in Figure 4, a definite correlation existed between circumcision status and the extent to which the parents were informed of the pros and cons of circumcision; uncircumcised boys' parents were more informed than parents of circumcised boys, at $74.0 \%$ versus $66.3 \%$, respectively. This trend regarding knowledge is much more pronounced in the boys themselves (Figure 5); informed boys were more than three times less likely to be circumcised. Since a correlation exists between information and circumcision status, we analyzed which media types were important sources of information regarding circumcision. Figure 6 shows information sources used by parents; the internet is the

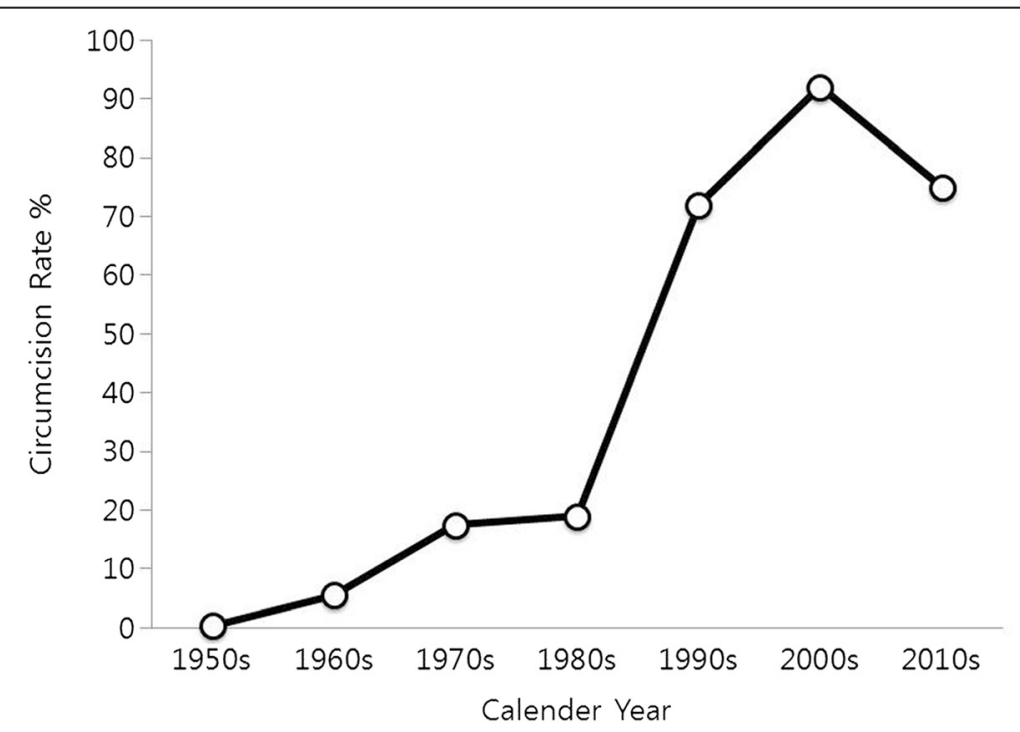

Figure 2 The circumcision rate of then-20-year-olds as a function of calendar year. The data are combined from ref. [2] and the present study. 


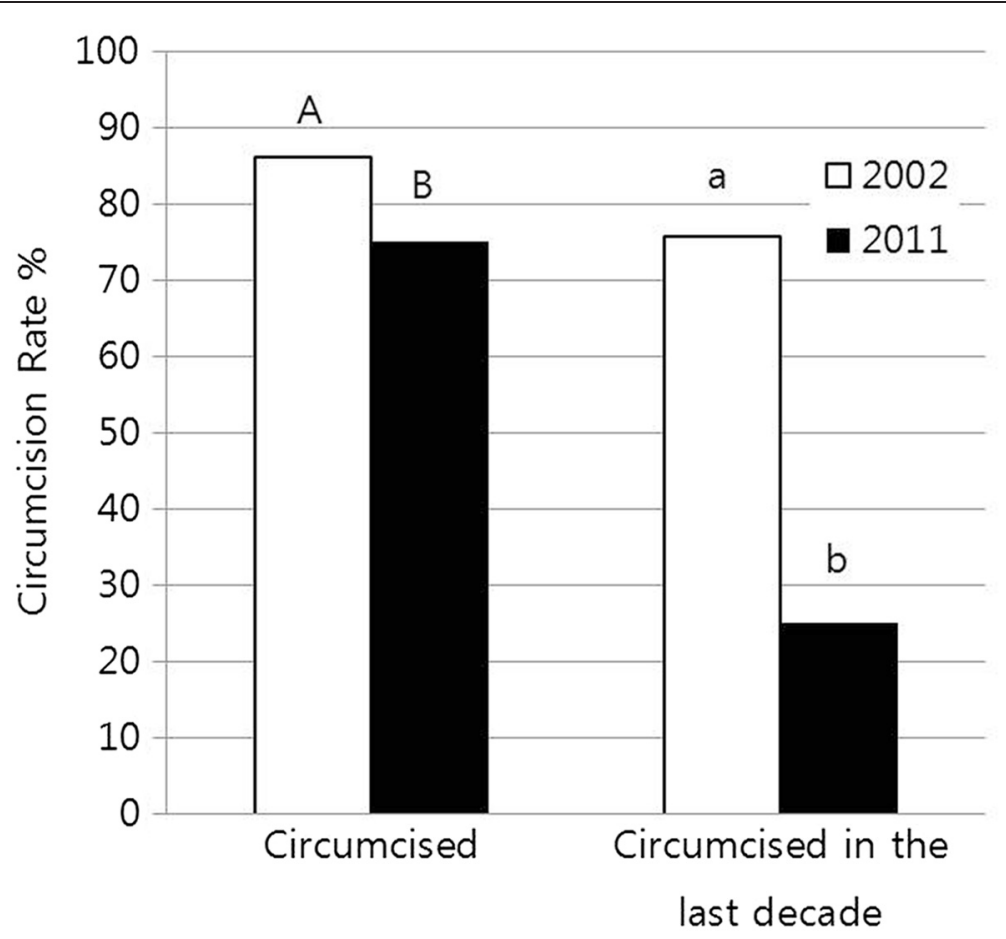

Figure 3 The circumcision rate and the percentage of circumcisions in the last decade for South Korean males aged 14-29.

$A, B$ Significantly different circumcision rates between 2002 and $2011(p<0.05)$. ${ }^{a, b}$ Significantly different circumcision rates in the last decade between 2002 and 2011 ( $p<0.05)$.

most popular source, followed relatively evenly by newspapers, books, lectures, and TV. Interestingly, the uncircumcised boys obtained their information overwhelmingly from the internet, whereas the circumcised population also relied on newspapers (Figure 7).

\section{Discussion}

In English-speaking countries, the circumcision rate has been declining or is already fairly low; e.g., $<5.6 \%$ for England and $<2 \%$ for New Zealand $[8,9]$. Even in the US, a steady decline in the neonatal circumcision rate has

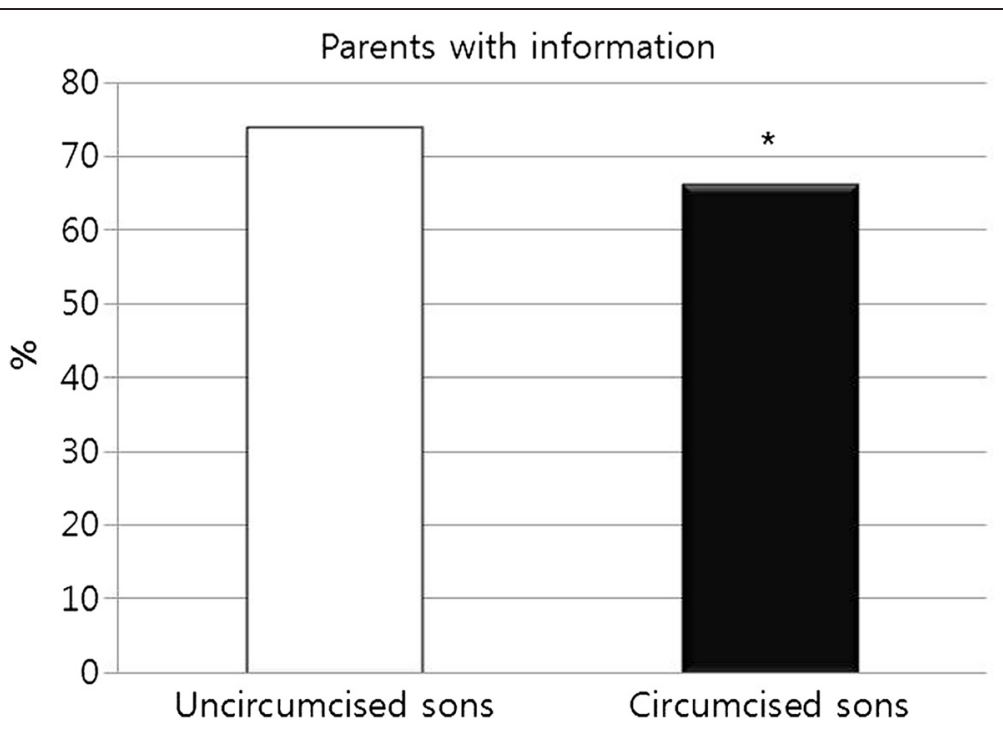

Figure 4 Circumcision status in boys aged 0-29 years as a function of parental use of information for and against circumcision from sources other than person-to-person oral communication. Men aged 29 years were also counted as boys when the information was provided by a parent. ${ }^{*}$ Significantly different percentages of parents with information between uncircumcised and circumcised sons ( $\left.p<0.05\right)$. 


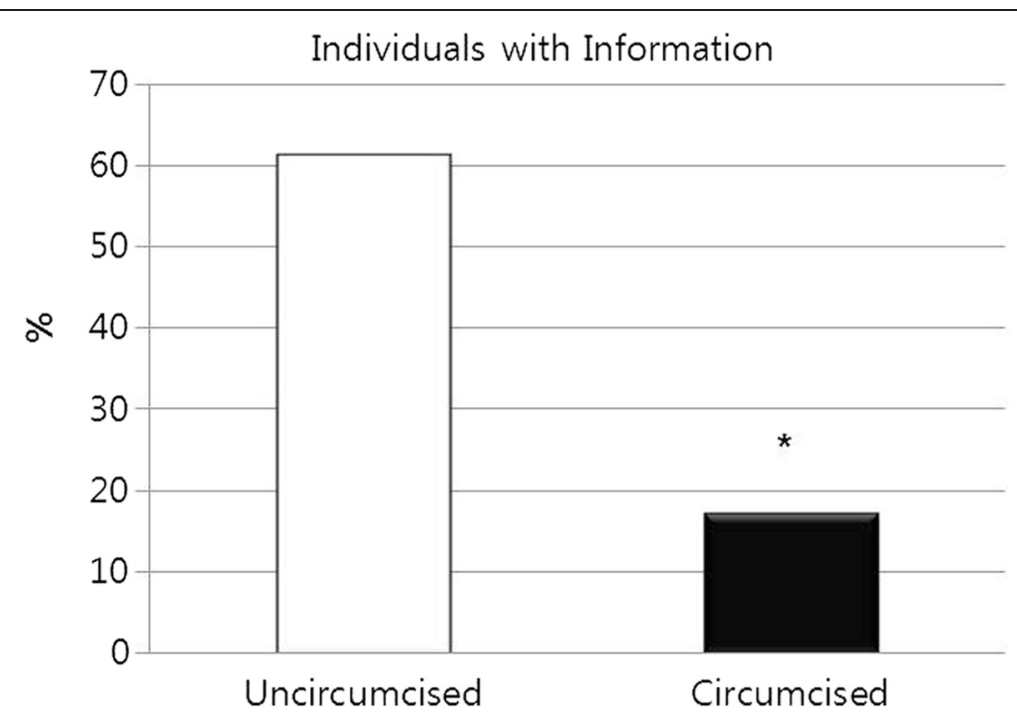

Figure 5 Circumcision status as a function of use of information for and against circumcision from sources other than person-toperson oral communication, for men aged 18-64. ${ }^{*}$ Significantly different percentages of individuals with information between presently uncircumcised and circumcised males $(p<0.05)$.

been reported [6]. To our surprise, we found that the circumcision rate decreased substantially in South Korea, much more than in the US. Both the rapid increase in the period from $1980-2000$ and the recent decrease are more drastic when compared to their counterpart periods in US history. In the present study, the current circumcision rate of $75.8 \%$ (ages 14-29) is 11.1 percentage points lower than the $86.3 \%$ value observed in 2002. This decrease of $10.5 \%$ per decade is about two times faster than that reported in a US neonatal circumcision rate study by Zhang et al. [6], which reported a decline of about $5 \%$ for the last decade. The percentage of boys circumcised in the last decade was only $25.2 \%$, which is a dramatic decrease compared to the $75.7 \%$ reported in 2002 . This result strongly suggests that the majority of currently circumcised males underwent the procedure prior to 2002 .

Using a questionnaire included in our survey, we identified the wide range of information that has become newly available over the last decade as the chief cause of this decline in circumcision. It is interesting, however, that the vast majority of the information available has been and still is about the benefits of circumcision and the active promotion of the procedure for males of all ages. The change observed in the last decade is that, prior to $1999,100 \%$ of the information was pro-circumcision, including the best age for circumcision, the sexual enhancement gained through circumcision, increased hygiene, medical benefits, etc. Only after 1999 has some information against circumcision become available.

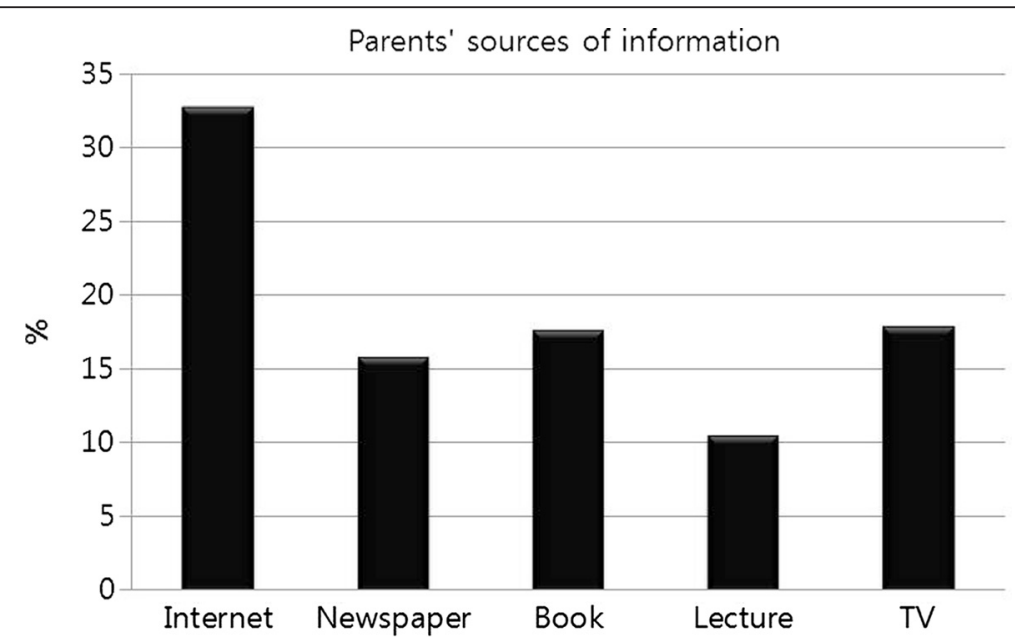

Figure 6 Circumcision information sources for parents. 


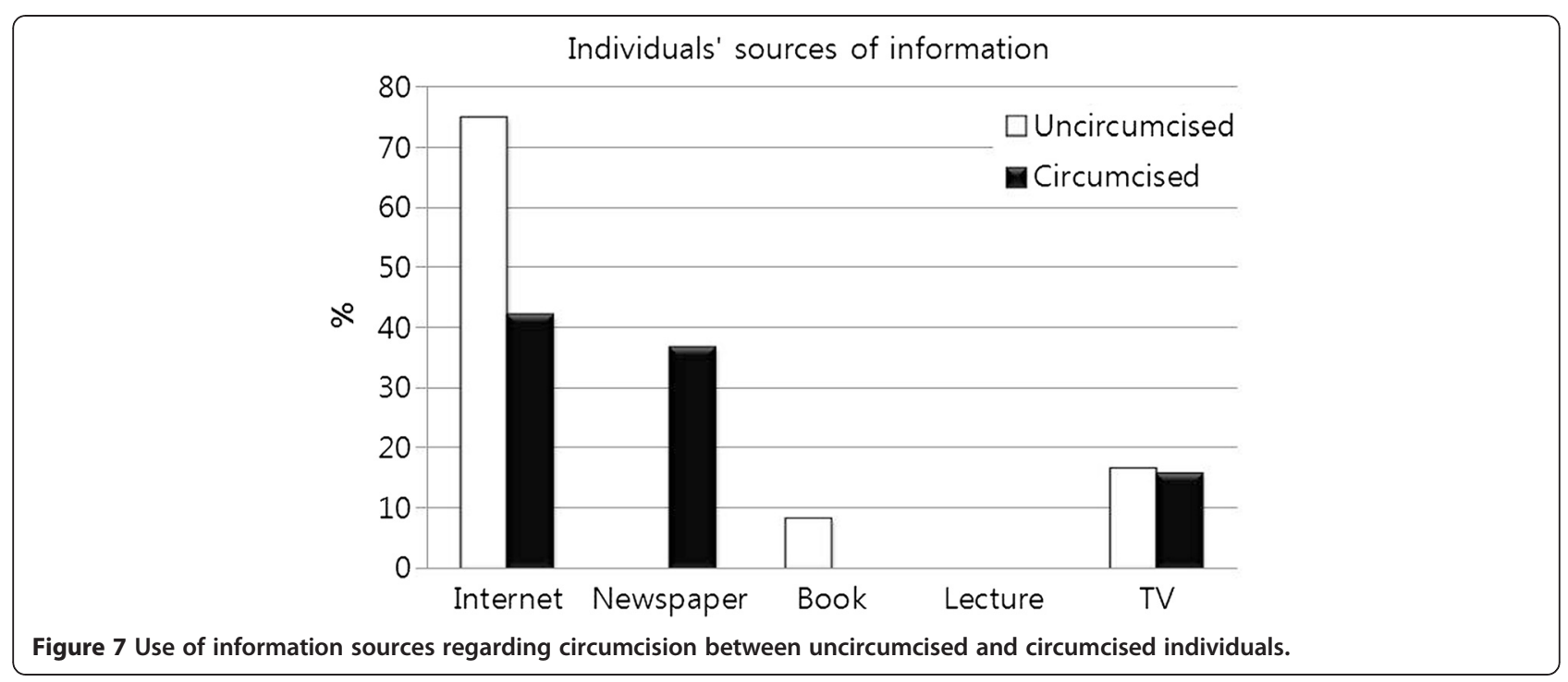

Therefore, it is tempting to speculate that the very existence of information about the history of Korean circumcision, its contrary nature relative to a longstanding tradition, its introduction by the US military, etc., has been extremely influential on the decision-making process regarding circumcision. Although only $3 \%$ of Korean internet sites, using the most the popular Korean search engine 'naver' (http://naver.com), are against indiscriminate circumcision and $97 \%$ are for circumcision (data not shown; searched by the authors); these minority sites provide information-seeking individuals sufficient reason to avoid circumcision. It should be mentioned that newspaper articles [10] are less extreme in their promotion of circumcision; only $80 \%$ of articles tend to promote the benefits of circumcision.

We discuss the implication of declining circumcision rates in South Korea in view of the diverse global attitudes regarding circumcision. The recent increase in the circumcision rate through mass-circumcision in subSaharan Africa has largely been driven by the supposed correlation between human immunodeficiency virus (HIV) infection and lack of circumcision. However, despite widespread information on the supposed benefits of circumcision (including the alleged correlation between HIV and circumcision), the circumcision rate in the US has been declining. The present rapid increase in circumcision in such countries [11] as Uganda, Kenya, Botswana, Mozambique, Swaziland, Zambia, and Zimbabwe is analogous to the situation in South Korea in the years between 1960-1990 [1,2]. Interestingly, Tanzania, which has been a traditionally circumcising country as a rite of passage, is transforming itself into a medically circumcising one [4]. In Rwanda, which is essentially a noncircumcising nation, both medically and traditionally, the medical circumcision is being vigorously pursued
[5]. In this respect, African countries such as Rwanda closely resemble the South Korean situation of 50 years ago.

The onset of South Korean circumcision can be pinpointed to the years 1945-1950, with the ending of Japanese occupation of Korea, and the start of the US military government and the Korean War. The medicalization of circumcision happened between the years 1960-2000, where the circumcision rate soared from $10 \%$ to $90 \%$. In South Korea, a large campaign in support of circumcision was aimed at preventing cervical cancer and the spread of the human papilloma virus (HPV), whereas in present-day Africa, the motivation is to prevent the spread of HIV. In addition, only positive information for circumcision was available to Koreans in 1960-2000; this also seems to be the current case in many sub-Saharan African countries. Improved resources in the US and South Korea have rendered it unnecessary to practice mass circumcision; in subSaharan countries, the initial rapid increase in circumcision may be overtaken by the human inclination toward body preservation, aided by improved financial resources and standards of living.

The South African situation is interesting, as it is the African country with the highest standard of living but is also the one in which mass-circumcision is being criticized from within [12]. Circumcision in such English speaking countries as Great Britain, Australia, Canada, and New Zealand showed a rapid decline after an initial increase, although the overall circumcision rates were never as high as those in the US. The question is then whether South Africa, being another English speaking country, will follow the trends of these English speaking nations or whether the desire for HIV prevention benefits will cause the South African rate to go higher. 
One limitation of the present study is cross-sectional design and non-probability sampling inherent in internet survey using internet sites and emails etc. Similar sampling methods using internet were used in our 2002 study [2]. With wider usage of internet and email in the population, the present study may represent more general cross sectional sampling than the 2002 version. Clearly, further studies involving general population and probability sampling method are needed.

\section{Conclusion}

We contend that South Korean male circumcision has experienced a steep decline in the last decade: at 10.5\% over 10 years, which is about two times steeper than the current change in US rate. The cause for this decline seems to be the new wealth of information available about circumcision, particularly the realization that the procedure is not mandatory. The South Korean situation has implications for the present practices regarding circumcision in sub-Saharan African countries.

\section{Additional file}

Additional file 1: The questionnaire used in our survey; the questions were simplified to draw maximum response rate.

\section{Competing interests}

The authors declare that they have no competing interests.

\section{Authors' contribution}

DSK, SAK, and MGP participated the conception and design, acquisition of data, analysis, and interpretation of data. DSK and MGP participated in drafting the manuscript. All authors read and approved the final manuscript.

\section{Acknowledgements}

This work was supported by the National Research Foundation of Korea (NRF) grant funded by the Korea government (MEST) (No. 2011-0031428).

\section{Author details}

${ }^{1}$ Department of Physics and Astronomy, Seoul National University, Seoul, South Korea. ${ }^{2}$ Purun Ausung, Seoul, South Korea. ${ }^{3}$ Department of Animal Science and Technology, School of Bioresource and Bioscience, Chung-Ang University, Anseong, Gyeonggi-Do, South Korea.

Received: 26 April 2012 Accepted: 23 November 2012

Published: 11 December 2012

\section{References}

1. Kim DS, Lee JY, Pang MG: Male circumcision: a South Korean perspective. BJU Int 1999, 83(Suppl 1):28-33.

2. Pang $M G$, Kim DS: Extraordinarily high rates of male circumcision in South Korea: history and underlying causes. BJU Int 2002, 89:48-54.

3. Xiao J: The Classic of Xiao. http://www.tsoidug.org/Papers/ Xiao_Jing_Comment.pdf

4. Wambura M, Mwanga JR, Mosha JF, et al: Acceptability of medical male circumcision in the traditionally circumcising communities in Northern Tanzania. BMC Public Health 2011, 11:373.

5. Gasasira RA, Sarker M, Tsague L, et al: Determinants of circumcision and willingness to be circumcised by Rwandan men. BMC Public Health 2012 12:134R.

6. Zhang X, Shinde S, Kilmarx PH, et al: Trends in in-hospital newborn male circumcision-United States. 1999-2010. MMWR Morb Mortal Wkly Rep 2011, 60:1167-1168.
7. Kelly A, Kupul M, Fitzgerald L, et al: "Now we are in a different time; various bad diseases have come." Understanding men's acceptability of male circumcision for HIV prevention in a moderate prevalence setting. BMC Public Health 2012, 12:67.

8. Gordon A, Collin J: Save the normal foreskin. BMJ 1993, 306:1-2.

9. Shannon FT, Horwood LJ, Fergusson DM: Infant circumcision. New Zealand Med J 1979, 90:283.

10. Korea Press Foundation: Circumcision. http://www.kinds.or.kr

11. Wikipedia: Prevalence of Circumcision. http://en.wikipedia.org/wiki/ Prevalence_of_circumcision

12. Connolly C, Simbayi LC, Shanmugam R, et al: Male circumcision and its relationship to HIV infection in South Africa: results of a national survey in 2002. S Afr Med J 2008, 98:789-794.

doi:10.1186/1471-2458-12-1067

Cite this article as: Kim et al:: Decline in male circumcision in South Korea. BMC Public Health 2012 12:1067.

\section{Submit your next manuscript to BioMed Central and take full advantage of:}

- Convenient online submission

- Thorough peer review

- No space constraints or color figure charges

- Immediate publication on acceptance

- Inclusion in PubMed, CAS, Scopus and Google Scholar

- Research which is freely available for redistribution 